\title{
Ignition and Growth Modeling of Detonating TATB Cones and Arcs
}

C. M. Tarver, S. K. Chidester

June 14, 2007

2007 APS SHock Compression of Condensed Matter Kohala Coast, HI, United States June 23, 2007 through June 29, 2007 
This document was prepared as an account of work sponsored by an agency of the United States government. Neither the United States government nor Lawrence Livermore National Security, LLC, nor any of their employees makes any warranty, expressed or implied, or assumes any legal liability or responsibility for the accuracy, completeness, or usefulness of any information, apparatus, product, or process disclosed, or represents that its use would not infringe privately owned rights. Reference herein to any specific commercial product, process, or service by trade name, trademark, manufacturer, or otherwise does not necessarily constitute or imply its endorsement, recommendation, or favoring by the United States government or Lawrence Livermore National Security, LLC. The views and opinions of authors expressed herein do not necessarily state or reflect those of the United States government or Lawrence Livermore National Security, LLC, and shall not be used for advertising or product endorsement purposes. 


\title{
IGNITION AND GROWTH MODELING OF DETONATING TATB CONES AND ARCS
}

\author{
Craig M. Tarver and Steven K. Chidester
}

Lawrence Livermore National Laboratory, Livermore, CA 94550

\begin{abstract}
Previously established Ignition and Growth reactive flow models for the detonating triaminotrinitrobenzene (TATB) based plastic bonded explosives LX-17 and PBX 9502 are applied to recent experimental detonation propagation/failure experiments using unconfined cones, confined arcs, and unconfined arcs. The conical experiments are initially overdriven by the convergent geometry and then fail to detonate at smaller diameters than do unconfined cylindrical charges as the radial rarefaction wave lowers the shock pressure and temperature and thus decreases the chemical energy release rate. Unconfined TATB arcs detonate more slowly than cylindrical charges on the inner surface and exhibit large phase velocities on the outer surface. Confinement reduces but does not eliminate these effects. The Ignition and Growth model calculations based on parameters normalized to a great deal of one-, two- and three-dimensional detonation propagation data reproduce these features and agree closely with experimental detonation velocity and arrival time data.
\end{abstract}

Keywords: Explosive, Triaminotrinitrobenzene, Detonation failure, Ignition and Growth PACS: $82.33 . V x, 82.40 . \mathrm{Fp}$

\section{INTRODUCTION}

The Ignition and Growth reactive flow model [1] simulates shock initiation and detonation wave propagation of triaminotrinitrobenzene (TATB) based plastic bonded explosives (PBXs). A great deal of 1D, 2D and 3D experimental data has been used to parameterize detonation models for LX-17 (92.5\% TATB plus $7.5 \%$ KelF binder) and PBX 9502 (95\% TATB plus 5\% KelF binder) [2-5]. Recently several new sets of experimental TATB PBX detonation data have been published. Salyer and Hill [6] detonated conical PBX 9502 charges with various included angles, measured the detonation velocities along the conical edges, and observed the failure of the detonation wave at certain angles. Ferm et al. [7] reported proton radiographical observations of these failing waves. Lubyatinsky et al. [8] measured arrival times at the inner and outer edges of $180^{\circ}$ ribs confined by steel or PMMA. Zhao et al. [9] reported arrival times on the inner and outer edges of $125^{\circ}$ arcs of a 95\% TATB PBX confined by steel. Two experiments on unconfined $90^{\circ} \mathrm{LX}-17$ arc geometries [10] are included. All of this experimental data is compared to Ignition and Growth simulations.

\section{IGNITION AND GROWTH MODELING}

The Ignition and Growth reactive flow model [1] uses two Jones-Wilkins-Lee (JWL) equations of state in the form:

$$
\mathrm{p}=\mathrm{Ae}^{-\mathrm{R} 1 \mathrm{~V}}+\mathrm{Be}^{-\mathrm{R} 2 \mathrm{~V}}+\omega \mathrm{C}_{\mathrm{v}} \mathrm{T} / \mathrm{V}
$$


where $\mathrm{p}$ is pressure in Megabars, $\mathrm{V}$ is relative volume, $\mathrm{T}$ is temperature, $\omega$ is the Gruneisen coefficient, $\mathrm{C}_{\mathrm{V}}$ is the average heat capacity, and $\mathrm{A}, \mathrm{B}, \mathrm{R}_{1}$ and $\mathrm{R}_{2}$ are constants. The reaction rate equation is:

$$
\begin{aligned}
& d F / d t=\underbrace{I(1-F)^{b}\left(\rho / \rho_{0}-1-a\right)^{x}}_{0<F<F_{I g \max }}+ \\
& \underbrace{G_{1}(1-F)^{c} F^{d} p^{y}}_{0<F<F_{G_{1} \max }}+\underbrace{G_{2}(1-F)^{e} F^{g} p^{z}}_{F_{G_{2} \min }<F<1}
\end{aligned}
$$

where $\mathrm{F}$ is fraction reacted, $\mathrm{t}$ is time in $\mu \mathrm{s}, \rho$ is the current density, $\rho_{\mathrm{O}}$ is the initial density, $p$ is pressure in Mbar, and $\mathrm{I}_{1} \mathrm{G}_{1}, \mathrm{G}_{2}, \mathrm{a}, \mathrm{b}, \mathrm{c}, \mathrm{d}, \mathrm{e}, \mathrm{g}$, $\mathrm{x}, \mathrm{y}$, and $\mathrm{z}$ are constants. The LX-17 parameters are listed by Tarver [4] and the PBX 9502 parameters by Garcia and Tarver [5].

\section{CONICAL DETONATION RESULTS}

Salyer and Hill [6] reported the edge detonation velocities as functions of inverse radius of PBX 9502 cones with included angles of $10^{\circ}, 20^{\circ}, 30^{\circ}, 40^{\circ}, 80^{\circ}$ and $90^{\circ}$. As the steady PBX 9502 waves enter the converging cones, they are overdriven to higher velocities and shock pressures and temperatures than the Chapman-Jouguet (C-J) and von Neumann spike values [11]. At $40^{\circ}, 80^{\circ}$ and $90^{\circ}$, the converging detonation waves propagate through the entire cones at greater than $\mathrm{C}-\mathrm{J}$ velocities. At $10^{\circ}, 20^{\circ}$ and $30^{\circ}$, the convergence effects are overcome by rarefaction waves, which reduce the reaction rates until they separate from the shock fronts. Then the detonation waves immediately fail. These 2D conical experiments were modeled using 20 zones per $\mathrm{mm}$ and the PBX 9502 parameters.

Figure 1 shows the experimental and calculated edge velocities as functions of inverse cone radius for the $40^{\circ}, 80^{\circ}$ and $90^{\circ}$ cones along with the unconfined detonation velocity-inverse radius curve. The calculated detonation waves detonated to the tips of the cones. The $80^{\circ}$ and $90^{\circ}$ cones remained overdriven at edge velocities exceeding 10 $\mathrm{km} / \mathrm{s}$. Figure 2 shows the $10^{\circ}, 20^{\circ}$ and $30^{\circ}$ comparisons. These calculated detonation waves failed to detonate to the tips of the cones. The calculated failures occurred at a larger radius than experiment for the $30^{\circ}$ cone and smaller radii than the $10^{\circ}$ and $20^{\circ}$ cone tests.

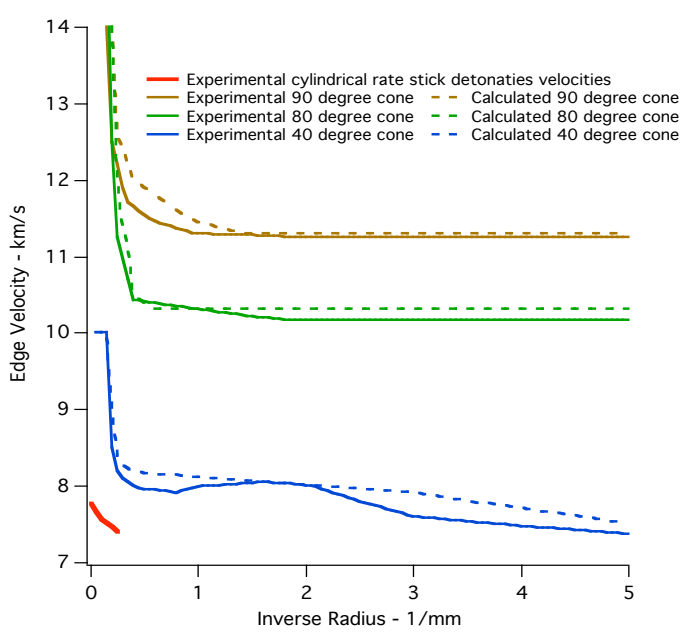

FIGURE 1. Experimental and calculated edge velocities versus inverse radius for the $40^{\circ}, 80^{\circ}$ and $90^{\circ} \mathrm{PBX} 9502$ cones

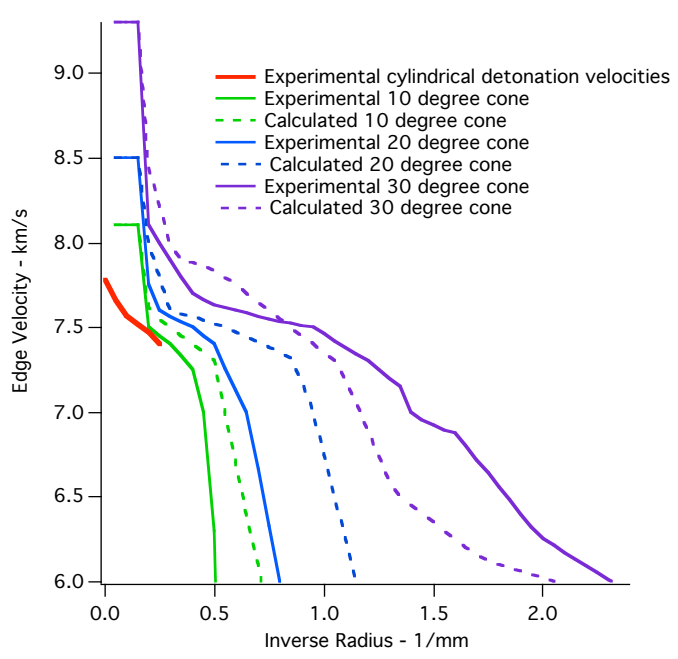

FIGURE 2. Experimental and calculated edge velocities versus inverse radius for the $10^{\circ}, 20^{\circ}$ and $30^{\circ} \mathrm{PBX} 9502$ cones 


\section{UNCONFINED AND CONFINED ARCS}

Unconfined LX-17 $90^{\circ}$ arc tests were fired by J. Lyle and B. Hayes [10]. Lyle's arc had an inner radius of $8.89 \mathrm{~cm}$ and an outer radius of $11.43 \mathrm{~cm}$, while Hayes' arc had a $6.35 \mathrm{~cm}$ inner radius and a $10.16 \mathrm{~cm}$ outer radius. Figure 3 shows the experimental and calculated wave velocities at various angles along the outer edge of Lyle's arc. The average calculated phase velocity from $0^{\circ}$ to $90^{\circ}$ is $8.781 \mathrm{~km} / \mathrm{s}$, while the measured value is $8.667 \mathrm{~km} / \mathrm{s}$ for $0^{\circ}$ to $85^{\circ}$. The inner surface pins measured a constant velocity of $7.289 \mathrm{~km} / \mathrm{s}$ from $0^{\circ}$ to $84^{\circ}$, while the calculated inner surface velocity was 7.241 $\mathrm{km} / \mathrm{s}$. For the Hayes' arc, the measured inner edge velocity was $7.03 \mathrm{~km} / \mathrm{s}$, while the calculated value was $7.042 \mathrm{~km} / \mathrm{s}$. The measured outer surface velocity was $10.07 \mathrm{~km} / \mathrm{s}$, and the calculated value was $9.75 \mathrm{~km} / \mathrm{s}$. The experimental and calculated initial wave breakouts were $3 \mathrm{~mm}$ from the inner edge.

A 95\% TATB explosive arc experiment with an inner radius of $7 \mathrm{~cm}$ and an outer radius of $10 \mathrm{~mm}$ confined on both edges by $0.5 \mathrm{~cm}$ of steel was done by Zhou et al.[8] Arrival times at $60^{\circ}, 90^{\circ}$ and $125^{\circ}$ were reported. The measured

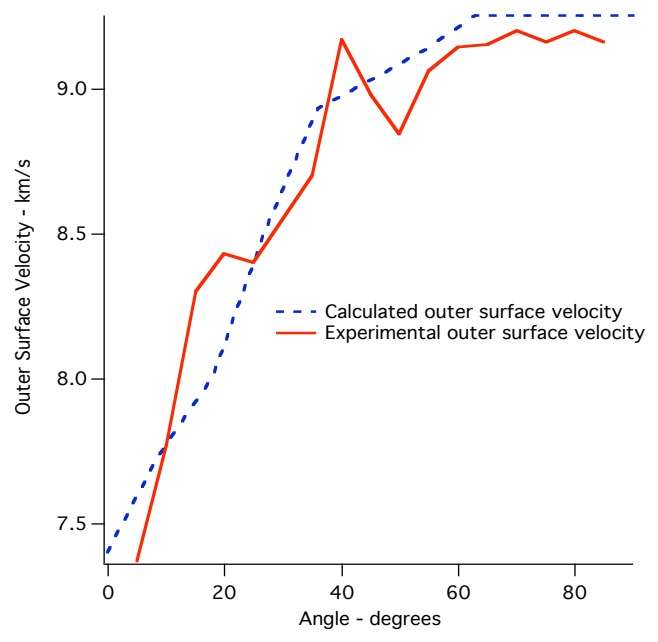

FIGURE 3. Experimental and calculated outer surface velocities versus angle for the Lyle LX-17 arc inner edge velocity was $7.284 \mathrm{~km} / \mathrm{s}$, and the outer edge velocity was $10.31 \mathrm{~km} / \mathrm{s}$. PBX 9502 model velocities were $7.258 \mathrm{~km} / \mathrm{s}$ for the inner edge and $10.23 \mathrm{~km} / \mathrm{s}$ for the outer edge.

A set of confined TATB arc experiments was published by Lubyatinsky et al. [9]. These experiments used $180^{\circ}$ TATB explosive arcs with outer radii of $6 \mathrm{~cm}$ and inner radii of 3,4 and $5 \mathrm{~cm}$ confined on both edges by $1 \mathrm{~cm}$ of steel or PMMA. Time of arrival pins were placed every $15^{\circ}$ degrees along both explosive edges. The edge wave velocities measured for the $180^{\circ}$ arcs were slightly less than those calculated by the LX-17 comparison. Figure 4 contains the experimental and calculated arrival time differences for the three LX-17 thicknesses with steel confinement, while Fig. 5 shows the arrival time differences for PMMA confinement. The calculated and experimental arrival time differences agree closely for the steel confined charges, while the calculated differences are larger than those measured for the $20 \mathrm{~mm}$ and $30 \mathrm{~mm}$ thick arcs confined by PMMA. The experiment and the calculation show failure of the $10 \mathrm{~mm}$ thick TATB arc confined by PMMA after about $90^{\circ}$ of travel.

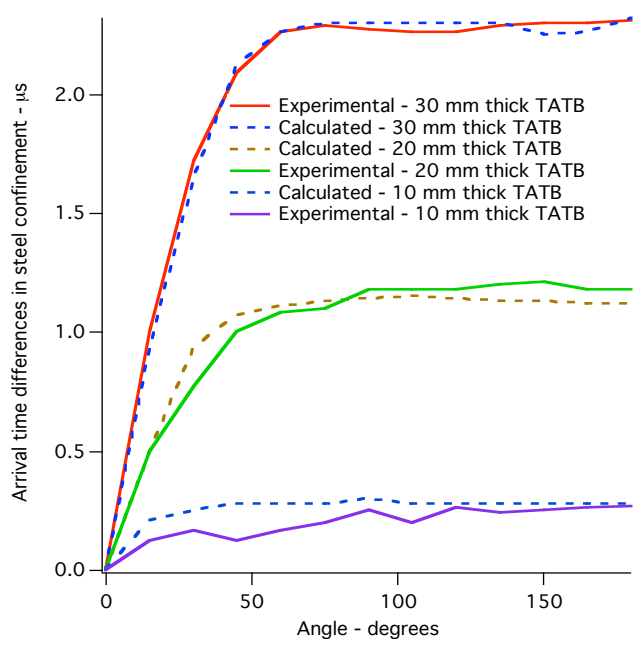

FIGURE 4. Experimental and calculated arrival time differences for $180^{\circ} \mathrm{LX}-17$ arcs in steel confinement 


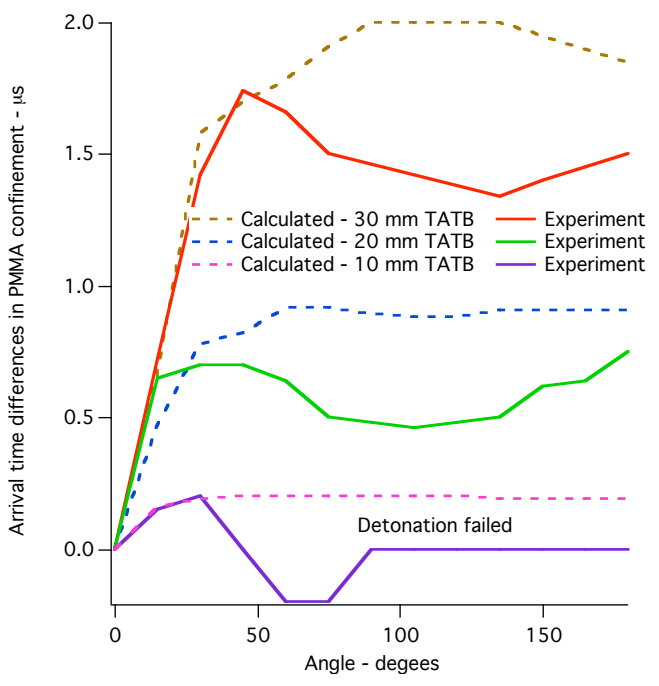

FIGURE 5. Experimental and calculated arrival time differences for LX-17 Arcs in PMMA

\section{SUMMARY}

The LX-17 and PBX 9502 Ignition and Growth detonation wave models, previously normalized to a great deal of 1D, 2D and 3D experimental data, accurately calculated recently reported results of several conical convergence/failure, unconfined arc and confined arc experiments. It is essential that these models accurately predict the effects of various geometries, degrees of confinement and initial conditions on steady and non-steady state detonation wave propagation. Therefore they are tested against all new experimental data as it becomes available. In this case, the existing LX-17 and PBX 9502 parameters were successfully validated against several new types of experimental data.

\section{ACKNOWLEDGEMENTS}

This work was performed under the auspices of the U. S. Department of Energy by the University of California, Lawrence Livermore National Laboratory under Contract No. W-7405-Eng-48.

\section{REFERENCES}

1. Tarver, C. M., Hallquist, J. O., and Erikson, L. M., "Modeling Short Pulse Duration Shock Initiation of Solid Explosives," Eighth Symposium (International) on Detonation, Naval Surface Weapons Center NSWC MP86-194, Albuquerque, NM, 1985, pp. 951-961.

2. Tarver, C. M., Breithaupt, R. D. and Kury. J. W., "Detonation Waves in Triaminotrinitrobenzene," $J$ Appl. Phys. 82, 3771-3782 (1997).

3. Tarver, C. M. and McGuire, E. M., "Reactive Flow Modeling of the Interaction of TATB Detonation Waves with inert Materials," Twelfth International Detonation Symposium, Office of Naval Research ONR 333-05-2, San Diego, CA, August, 2002, pp. 641-649.

4. Tarver, C. M., "Ignition and Growth Modeling of LX17 Hockey puck Experiments," Propellants, Explosives, Pyrotechnics 30, 109-117 (2005).

5. Garcia, M. L. and Tarver, C. M., "Three-Dimensional Ignition and Growth Modeling of Prism Failure Tests on PBX 9502," Thirteenth International Detonation Symposium, Norfolk, VA, July 23 - 28, 2006, in press.

6. Salyer, T. R. and Hill, L. G., "The Dynamics of Detonation Failure in Conical PBX 9502 Charges," Thirteenth International Detonation Symposium, Norfolk, VA, July 23 - 28, 2006, in press.

7. Ferm, E. N., Marium, F. G. and the LANSCE Proton Radiography Team, "Proton Radiography Observations of the Failure of a Detonation Wave to propagate to the End of a Conical Charge," Shock Compression of Condensed Matter - 2005, AIP Conference Proceedings 845, Baltimore, MD, 2006, pp. $968-971$.

8. Lubyatinsky, S. N., Batalov, S. V., Garmashev, A. Y., Israelyan, V. G., Kostitsyn, O. V., Loboiko, B. G., Pashentsev, V. A., Smirnov, E. B. and Filin, V. P., "Detonation Propagation in $180^{\circ}$ Ribs of an Insensitive High Explosive," Shock Compression of Condensed Matter - 2003, AIP Conference Proceedings 706, Portland. OR, 2004, pp. 859-862.

9. Zhao, T., Li, Q., Zhao, F., Sun, C. Han, L., and Gao, W., "An Experimental Study of Detonation Propagation in the Arc Insensitive High Explosive," Eleventh International Detonation Symposium, Office of Naval Research ONR 33300-5, Snowmass, CO, August, 1998, pp. 1023-1028.

10. Souers, P. C., Anderson, S. R., Hayes, B., Lyle, J., Lee, E. L., McGuire, E. M., and Tarver, C. M., "Corner Turning Rib Tests on LX-17," Propellants, Explosives, Pyrotechnics 23, 200-207 (1998).

11. Green, L. G., Tarver, C. M. and Erskine, D. J., "Reaction Zone Structure in Supracompressed Detonating Explosives," Ninth Symposium (International) on Detonation, Office of the Chief of Naval Research OCNR 113291-7, Portland, OR, August, 1989, pp. 670-682. 